\title{
Correction to: microRNA-124 inhibits bone metastasis of breast cancer by repressing Interleukin-11
}

Wei-Luo Cai ${ }^{1,2+}$, Wen-Ding Huang ${ }^{1 \dagger}$, Bo $\mathrm{Li}^{2 \dagger}$, Tian-Rui Chen ${ }^{2 \dagger}$, Zhen-Xi Li ${ }^{2}$, Cheng-Long Zhao ${ }^{2}$, Heng-Yu Li $^{3}$, Yan-Mei $\mathrm{Wu}^{3}$, Wang-Jun Yan ${ }^{1,2^{*}}$ and Jian-Ru Xiao ${ }^{2^{*}}$

\section{Correction to: Molecular Cancer (2018) 17:9 \\ https://doi.org/10.1186/s12943-017-0746-0}

After publication of the article [1], the authors reported errors of inter-duplication in Fig. 4c. As shown in the original Fig. 4c, the "TRAP staining" images of "MDA-MB-231 NC-CM" and "MDA-MB-231 miR-124CM" were shown identical to "i-miR-124-CM + IL-11 $\mathrm{Ab}$ " and "i-NC-CM+ IL-11 Ab" group in Fig. 6b. The authors have confirmed that the "TRAP staining" images of "i-miR-124-CM + IL-11 Ab" and "i-NC-CM+ IL-11 $A b "$ in Fig. 6b were mistakenly presented in the original Fig. 4c. This mistake was caused by unintentionally covering the correct image during figure preparation, which is reflected by the original images. The updated figure (Fig. 4c) is included in this correction. The correction does not affect the findings or conclusions of the article. The authors apologize for any inconvenience that the inaccuracy may have caused.

The correct figures are updated below.

The original article can be found online at https://doi.org/10.1186/s12943017-0746-0.

*Correspondence: 13917966770@163.com; jianruxiao83@163.com

${ }^{+}$Wei-Luo Cai, Wen-Ding Huang, Bo Li and Tian-Rui Chen contributed equally to this work.

'Department of Musculoskeletal Tumor, Fudan University Shanghai Cancer Center; Department of Oncology, Shanghai Medical College, Fudan University, Shanghai 200032, China

${ }^{2}$ Spine Tumor Center, Changzheng Hospital, Second Military Medical University, Shanghai 200003, China

Full list of author information is available at the end of the article

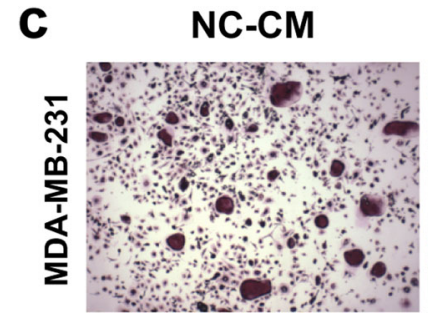

miR-124-CM

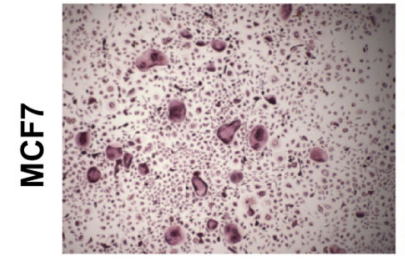

NC-CM

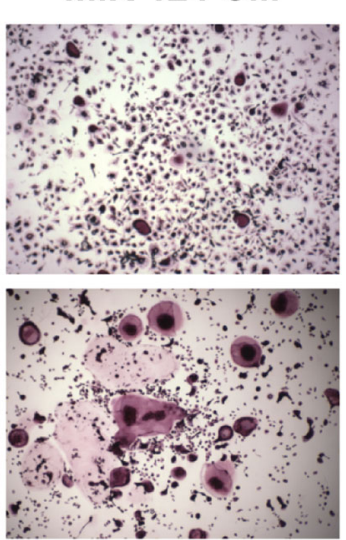

in-miR-124-CM

Author details

'Department of Musculoskeletal Tumor, Fudan University Shanghai Cancer Center; Department of Oncology, Shanghai Medical College, Fudan University, Shanghai 200032, China. ${ }^{2}$ Spine Tumor Center, Changzheng Hospital, Second Military Medical University, Shanghai 200003, China.

${ }^{3}$ Department of Breast and Thyroid Surgery, General Surgery, Changhai Hospital, Second Military Medical University, Shanghai 200433, China.

Published online: 27 June 2020

\section{Reference}

1. Cai W, Huang W, Li B, Chen T, Li Z, Zhao C, Li H, Wu Y, Yan W, Xiao J. microRNA124 inhibits bone metastasis of breast cancer by repressing Interleukin-11. Mol Cancer. 2018;17(1):9. https://doi.org/10.1186/s12943-017-0746-0.

(c) The Author(s). 2020 Open Access This article is licensed under a Creative Commons Attribution 4.0 International License, which permits use, sharing, adaptation, distribution and reproduction in any medium or format, as long as you give appropriate credit to the original author(s) and the source, provide a link to the Creative Commons licence, and indicate if changes were made. The images or other third party material in this article are included in the article's Creative Commons licence, unless indicated otherwise in a credit line to the material. If material is not included in the article's Creative Commons licence and your intended use is not permitted by statutory regulation or exceeds the permitted use, you will need to obtain permission directly from the copyright holder. To view a copy of this licence, visit http://creativecommons.org/licenses/by/4.0/ The Creative Commons Public Domain Dedication waiver (http://creativecommons.org/publicdomain/zero/1.0/) applies to the data made available in this article, unless otherwise stated in a credit line to the data. 